\title{
Direito À Saúde Intrínseco ao Campo da Seguridade Social
}

\author{
RIGHTTO HEALTH WITHIN SOCIAL SECURITY
}

Arthur Bragança de Vasconcellos Weintraub $b^{(*)}$

\section{RESUMO}

Foram examinados os liames entre as três vertentes da Seguridade Social no Brasil: Previdência Social, Assistência Social e Saúde. Há uma conexão constitucional entre estas vertentes englobadas no contexto da Seguridade Social que não pode ser esquecida. Qualquer análise científica ou técnica sobre Direito Sanitário ou sobre o direito à saúde necessita de uma fundamentação ligada à Seguridade Social.

\section{Palavras-chave}

Direito à Saúde; Direito Sanitário; Seguridade Social; Previdência Social; Assistência Social; Saúde.

\section{ABSTRACT}

This article has evaluated the connection involving the three branches of Social Security in Brazil: Pension System, Social Assistance and Health). There is a constitutional relationship between those branches that can not be forgotten. A Social Security ground is required in any scientific or technical analysis concerning Healthy Law or right to health.

\section{Key-words}

Right to Health; Healthy Law; Social Security; Pension System; Social Assistance; Health.

(*) Graduado, Mestre e Doutor em Direito Previdenciário pela USP, pesquisador convidado em Harvard (com o apoio da FAPESP), Advogado e Professor Concursado de Direito da Faculdade de Saúde Pública da USP. Email:arthurprevidencia@yahoo.com.br

Recebido: 27.8.05. Aprovado: 6.10.05 


\section{CONTEXTO GERAL DA SEGURIDADE SOCIAL}

O direito fundamental à saúde permeia aspectos biológicos, físicos, ambientais, psicológicos e sociais das pessoas. Um indivíduo pode estar saudável num momento efêmero. Sendo sua qualidade de vida sofrível, fatalmente há conseqüências quanto à salubridade de sua existência.

Norberto Bobbio sublinha a busca de uma melhor qualidade de vida como uma das tendências mais marcantes do mundo atual(1). Bobbio assevera que vivenciamos a chamada "era dos direitos"(2), ressaltando a relevância dos direitos fundamentais.

O caráter fundamental da Seguridade Social se revela na proteção da dignidade da pessoa humana, na proteção social e resvala as quatro geraçōes de direitos fundamentais, pendendo mais para os de segunda geração, como explanado a seguir:

1) Direitos Fundamentais de Primeira Geração: são aqueles relacionados à vida, à liberdade e à propriedade. Surgem no século XVIII, com as Declarações de Direitos (Declaração de Virgínia de 1776 e a Declaração dos Direitos do Homem e do Cidadão de 1789). Tais direitos afloram como resposta aos excessos do poder estatal, sendo liberdades públicas, ou direitos humanos individuais, constituindo verdadeira prerrogativa dos indivíduos em face do Estado. A vida, a liberdade e a propriedade são a quintessência dos elementos basilares do Estado Democrático de Direito. A Seguridade Social está pautada no trinômio vida-liberdade-propriedade.

2) Direitos Fundamentais de Segunda Geração: abarcam os chamados direitos sócio-econômicos, enquadrando-se especificamente a Seguridade Social. Surgiram diante do impacto da Revolução Industrial e dos problemas sociais oriundos desta época. Somente a consagração de liberdade e igualdade perante o Estado não gerava efetivamente sua fruição. Por isto, principalmente após a $1^{\text {a }}$ Guerra Mundial, as Cartas Constitucionais passaram a conferir tais direitos. Não bastava mais a mera garantia da vida, da liberdade e da propriedade, sendo necessária uma postura mais abrangente do Estado na assunção de riscos sociais em nome dos indivíduos. Observou-se uma liberdade por intermédio do próprio Estado, manifestando-se no sentido protetivo do homem enquanto ser que vive em coletividade, visando dar guarida aos chamados direitos humanos sociais.

3) Direitos Fundamentais de Terceira Geração: definidos como os direitos de titularidade de toda a população, de forma coletiva, interes-

(1) BOBBIO. Norberto. A era dos direitos. 8. ed. Rio de Janeiro: Campus, 1992. p. 67.

(2) Id., loc. cit. 
sando a todos e, de forma particular, a cada um, a exemplo do desenvolvimento econômico, qualidade de vida e meio ambiente. Objetivase a defesa dos direitos da coletividade, de forma difusa. A proteção abarcada pela Seguridade Social envolve certamente a qualidade de vida de maneira difusa.

4) $\mathrm{Na}$ evolução dos direitos fundamentais, existe a tendência ao reconhecimento dos chamados Direitos Fundamentais de Quarta Geração, resultado da globalização dos direitos fundamentais, no sentido de uma universalização no plano institucional, que corresponde à última fase de institucionalização do Estado Social. Essa Quarta Geração é composta pelos direitos à democracia e à informação (que devem tangenciar a Seguridade Social). Sem democracia e informação, o acesso das pessoas à malha de proteção social, que permeia a Seguridade Social, fica obnubilado. Sem democracia, a Seguridade Social se transforma em benevolência do tirano ou da oligarquia. Sem informação, a população desconhece seus direitos fundamentais.

A segurança social surge de um aprimoramento da própria civilização, uma evolução da postura estatal sobre a população. Não mais fica o indivíduo lançado à sua sorte, firmando o contrato social.

Segundo Ingo Wolfgang Sarlet ${ }^{(3)}$, direitos fundamentais e direitos humanos são distintos. Para ele, direitos fundamentais são direitos humanos (titular é ser humano) positivados constitucionalmente; e direitos humanos (gênero) estariam ligados mais ao Direito Internacional. Nossa Carta Magna foi expressa quanto aos direitos fundamentais.

Amiúde, mesmo no mundo científico, vemos o equívoco de alguns estudiosos do Direito em negar a vinculação do direito à saúde ao campo da Seguridade Social. Negam a relação entre Previdência Social, Assistência Social e Saúde, ignorando o próprio vínculo constitucional. A Ação Direta de Inconstitucionalidade - ADIn n. 2.028-DF mostra que a discussão existe até no campo judiciário (a Saúde tem tratamento constitucional próprio).

A mens legis e a mens legis/atoris na Constituição Federal de 1988 foram claríssimas: enquadrar como espécies do gênero Seguridade Social: Previdência Social, Assistência Social e Saúde - art. 194. Wagner Balera ${ }^{(4)}$ ensina que "a tríplice finalidade do sistema de seguridade social brasileiro se configura em diversas vertentes".

A preocupação governamental com o bem-estar dos trabalhadores não chega a ter dois séculos de existência. Os chamados riscos sociais, criados pela própria vida em sociedade, merecem resposta do Estado, que

(3) SARLET, Ingo Wolfgang. A eficácia dos direitos fundamentais. Porto Alegre: Livr. do Advogado, 2001. p. 33.

(4) BALERA, Wagner. Sistema de seguridade social. 2. ed. São Paulo: LTr, 2002. p. 13. 
depende dos impostos para existir e como contrapartida deve estruturar a rede de proteção dos trabalhadores aos riscos que só alguém que vive em sociedade tem.

Segundo Paul Durand ${ }^{(5)}$, os riscos sociais podem ser divididos em:

- infortunísticos: surgem com um revés da sorte, um infortúnio, uma desgraça, como a morte ou a invalidez;

- venturosos: manifestam-se por fatos ditosos, afortunados, felizes, como a sobrevivência da pessoa (a aposentadoria por idade é uma contrapartida ao fato da sobrevivência do segurado).

As contingências intrínsecas a estes eventos protegidos pelo Estado o são também à vida social; sendo tarefa estatal (decisão política) defini-las.

O homem é um ser gregário, com ímpeto genético de viver em sociedade, força genésica que traz então a necessidade desta organização coletiva. O Estado só existe mediante a aceitação das pessoas em acolher sua supremacia em relação a elas. Mas, o Estado deve arcar com a responsabilidade de proteger seus cidadãos perante os riscos inerentes ao estilo de vida pelo qual ele mesmo é responsável.

O conceito de Seguridade Social se condensa na função e nas providências do Estado no sentido de proteger a população em determinadas contingências adversas.

Esta conceituação se funda claramente em três alicerces:

- seguro social;

- proteção social; e

- justiça social.

A concepção de seguro social, proteção social e de justiça social não eram contemporâneas a Rousseau e sua obra sobre o contrato social; mas, os ideais iluministas cunharam as revoluçōes (americana e francesa) que mudariam o cenário mundial.

A proteção sobre determinadas contingências na vida dos trabalhadores (tais como acidentes do trabalho e velhice) foi se alicerçando a partir da Revolução Francesa, processo social e político (ocorrido entre 1789 e 1799) que ocasionou a queda de Luís XVI, a abolição da monarquia e a proclamação da República, pondo fim ao Antigo Regime.

A insurreição dos colonos norte-americanos contra os desmandos da Coroa inglesa também serviu de base para uma obrigatoriedade do Estado em explorar menos e proteger mais sua população.

(5) DURAND, Paul. La política contemporánea de seguridad social. Madrid: Ministerio de Trabajo y Seguridad Social, 1991. p. 55. 
Benjamin Franklin foi brilhante em seu idealismo durante a formação dos EUA. Este cientista e político que participou intensamente da independência americana contra a Inglaterra lembrava em suas obras que o país deve primar pela vida, liberdade e proteção do povo, e o povo tem direito constitucional à busca pela felicidade (pursue of happiness). A busca pela felicidade é um princípio da Declaração de Independência norte-americana. Ninguém, por este princípio, tem direito à felicidade. O princípio giza sim que todos têm o direito de buscá-la.

Noutro prisma, os abusos dos extratos sociais dominantes do Estado francês (nobreza, clero e burguesia) sobre os camponeses e demais trabaIhadores das classes populares, conjuntamente com a agitação intelectual estimulada pelo lluminismo, e o exemplo da Guerra da Independência norteamericana, foram definitivos para a mudança do status quo.

A justiça social e a proteção social depende dessa quebra de bloqueios de estamentos sociais. Se a pessoa não pode ascender socialmente e é tratada de forma diferente pelo Estado de acordo com seu extrato social, não há possibilidade de justiça nessa sociedade, tampouco de proteção geral dos cidadãos.

Houve uma Assembléia Nacional Constituinte francesa e posterior elaboração de uma Constituição. Na sua introdução, que foi denominada Declaração dos Direitos do Homem e do Cidadão, os delegados formularam os ideais da Revolução, sintetizados em três princípios: Liberté, Égalité, Fraternité.

A partir deste movimento revolucionário, que derrubou a nobreza francesa, começaram existir lutas sociais inéditas, atinentes também à Revolução Industrial, que culminaram na assunção pelo Estado de proteção de direitos conhecidos como sociais.

São direitos sociais, pois dependem da existência de uma sociedade organizada para existirem. São direitos dos integrantes da sociedade; direitos a serem garantidos pelo Estado, pelos Poderes Executivo, Legislativo e Judiciário.

\subsection{Contexto da Seguridade Social no Brasil}

O enquadramento constitucional pátrio é explícito ao comprovar a conexão entre Previdência Social, Assistência Social e Saúde ao contexto securitário social. Alguns princípios constitucionais são comuns a esse âmbito, notadamente a universalidade da cobertura e do atendimento e a seletividade e distributividade na prestação dos benefícios e serviços.

No campo jurídico, a seara da Seguridade Social é tão significativa que há patente autonomia doutrinária. Para Sergio Pinto Martins ${ }^{(6)}$ :

(6) MARTINS, Sérgio Pinto. Direito da seguridade social. 17. ed. São Paulo: Atlas, 2002. p. 44. 
"Direito da Seguridade Social é um conjunto de princípios, de regras e de instituições destinado a estabelecer um sistema de proteção social aos indivíduos contra contingências que os impeça de prover as suas necessidades pessoais básicas e de suas famílias, integrado por açōes de iniciativa do Poderes Públicos e da sociedade, visando assegurar os direitos relativos à saúde, à previdência e à assistência social."

Cabe enfatizar que Previdência Social, Assistência Social e Saúde são nitidamente direitos sociais.

O art. 60 da Constituição Federal de 1988 giza que são direitos sociais: a educação, a saúde, o trabalho, a moradia, o lazer, a segurança, a previdência social, a proteção à maternidade e à infância, a assistência aos desamparados. O saudoso professor Cesarino Jr. nos faz recordar a epítome de tais direitos sociais: proteção ao hipossuficiente. É a proteção ao hipossuficiente; mas, numa visão mais ampla é a proteção do Contrato Social.

A proteção social nas áreas da Previdência Social, Assistência Social e Saúde é a proteção da sociedade inteira. Ao contrário do que pensa o extrato social mais abastado no Brasil, o problema das camadas mais pobres (esmagadora maioria) é problema de todos. O Barão de Montesquie (7) ensina que a corrupção e o fim da ética social causaram até mesmo o fim de grandes impérios, como o grego e o romano:

"A tirania de um príncipe não leva a um Estado para mais perto da ruína do que, numa república, a indiferença pelo bem comum. A vantagem de um estado livre é que as rendas são aí melhor administradas. Mas, e quando não o são? A vantagem de um Estado livre é que ele não tem favoritos. Mas, quando isso não acontece, e em lugar dos amigos e parentes do príncipe é preciso fazer a fortuna dos parentes e amigos de todos os que participam do governo, tudo está perdido. As leis são contornadas mais perigosamente do que são violadas por um príncipe, o qual, sendo sempre o maior cidadão do Estado, tem mais interesse em sua conservação."

A legislação é coerente: arma-se uma rede de proteção social. O difícil é implementar o que está escrito. Com líderes nacionais como Getúlio Vargas, que dizia "a lei, ora a lei", desprezando totalmente a legislação e o princípio do rule of law, aplicar a lei no Brasil é sempre contra os padrōes culturais.

O art. 194 da Constituição Federal de 1988 indica os escopos de organização da Seguridade Social:

I - universalidade da cobertura e do atendimento:

O entendimento da universalidade em relação à Assistência Social e à Saúde é simples. Entretanto, temos que subdividir a universalidade subjetiva e objetiva.

(7) Considérations sur les causes de la grandeur des romains et de leur décadence, p. 29. 
Desdobra-se, portanto, a universalidade em subjetiva (referente a toda população), e objetiva (pautada nas contingências legais). Na saúde existe universalidade objetiva de cobertura e atendimento de todos os brasileiros e estrangeiros residentes aqui. Sublinhamos que por razões humanitárias o atendimento emergencial (dentro das possibilidades nacionais) de estrangeiros não residentes também é obrigatória.

II - uniformidade e de equivalência dos benefícios e serviços às populaçōes urbanas e rurais:

Esse princípio decorre da própria isonomia. Não deve haver diferenciação imotivada entre os trabalhadores urbanos e rurais.

III - seletividade e distributividade na prestação dos benefícios e serviços:

Nenhum recurso financeiro é ilimitado. Em verdade, os recursos no contexto da saúde estão escassos e deficitários. Dessa maneira, os gastos devem ser baseados num regime de prioridades na sua distribuição. Quem precisa mais, recebe mais. Peca o governo ao não aplicar recursos nessa área (recursos próprios, como $0,20 \%$ na CPMF).

IV - irredutibilidade do valor dos benefícios:

$\mathrm{O}$ inciso XV do art. 37 , e o inciso VI do art. $7^{\circ}$, ambos da Constituição Federal, asseguram, respectivamente, a irredutibilidade de subsídios aos funcionários públicos e de vencimentos dos empregados. Na Seguridade social, aplica-se o mesmo fator de proteção aos valores dos benefícios. Nossa atual Constituição foi erigida durante o período onde a inflação era estratosférica. Destarte, o constituinte visou a proteção do poder aquisitivo das pessoas (havendo uma reiteração, inclusive a do $\S 4^{\circ}$ do art. 201 da CF, onde é assegurado "o reajustamento dos benefícios para preservar-lhes, em caráter permanente, o valor real").

V - eqüidade na forma de participação no custeio:

Notamos aqui outro princípio decorrente da isonomia prevista no art. $5^{9}$, caput, da CF. Cada um deve contribuir de acordo com suas possibilidades, mediante proporcionalidade, ou até mesmo, progressividade de alíquotas das contribuições de custeio.

$\mathrm{VI}$ - diversidade da base de financiamento:

Segundo o art. 195 da Carta Magna, a seguridade social será financiada por toda a sociedade. Como, notoriamente, o Tesouro Nacional acaba sempre arcando com eventuais déficits da Previdência Social, de forma indireta, nesse aspecto, há um financiamento geral da sociedade.

A solidariedade social é essencial ao contexto. Este é um princípio geral da seguridade.

\subsubsection{Contexto da Saúde no Brasil}

A tendência de idéias de proteção social se alastrou pela Europa e pelo mundo, causando o chamado constitucionalismo social, pois as inova- 
çōes em prol dos cidadãos começaram a ser inseridas nos corpos das Constituições, ao invés de somente em leis esparsas. Estas Constituições determinavam a garantia pelo Estado de proteção das pessoas diante de riscos sociais característicos.

Na esfera da saúde não foi diferente. Sueli Gandolfi Dallari corrobora tal assertiva ${ }^{(8)}$ :

"A proteção da saúde é admitida no elenco das atividades do Estado liberal e recebe, portanto, um status constitucional. Isso significa que, apesar do empirismo que caracteriza a regulamentação das atividades de interesse para a proteção da saúde, as medidas de polícia administrativa relativas à tal proteção devem estar sob o manto da lei".

É um erro pensar que o fenômeno do constitucionalismo social se limitou à Europa. A primeira Constituição que conteve normas a respeito de um seguro social foi a mexicana (de 31 de janeiro de 1917).

A previsão da Constituição mexicana sobre seguridade social, inciso XXIX, a, do art. $123^{(9)}$, foi direta:

"Considera-se de utilidade pública a expedição da lei do seguro social, que compreenderá seguros de invalidez, de vida, de cessação involuntária do trabalho, de doença e acidentes e outros seguros com fins análogos."

Em seguida temos a Constituição de Weimar (de 11 de agosto de 1919), em seu art. $161^{(10)}$ :

"A União criará, com o concurso adequado dos segurados, um sistema global de seguros para a conservação da saúde e da capacidade de trabalho, a proteção da maternidade e a previdência contra faltas econômicas na velhice, na enfermidade e nas vicissitudes da vida."

O século XX acaba por sedimentar o ideário de proteção social ligada à saúde, onde o Estado tem o dever sanitário de prevenção e reparação. Sueli Gandolfi Dallari corrobora tal assertiva(11):

"No início do século XX encontra instaurada a proteção sanitária como política de governo. E são hierarquizadas três formas, hoje clássicas, de prevenção: a primária, que se preocupa com a eliminação das cau-

(8) DALLARI, Sueli Gandolfi. O princípio da precaução dever do estado ou protecionismo disfarçado? Disponivel em: <http://www.scielo.br/scielo.php?script=sci_arttext\&pid=S0102-88392002000200007> Acesso em 22.dez.2005.

(9) BUDIB, Alexandre Carlos. Benefícios de assistência social. Dissertação (Mestrado) - Pontifícia Universidade Católica. São Paulo, 2004. p. 20.

(10) Id. Ibid., p. 21.

(11) DALLARI, Sueli Gandolfi. op. cit. 
sas e condições de aparecimento das doenças, agindo sobre o ambiente (segurança nas estradas, saneamento básico, por exemplo) ou sobre o comportamento individual (exercício e dieta, por exemplo); a secundária ou prevenção específica, que busca impedir o aparecimento de doença determinada, por meio da vacinação, dos controles de saúde, da despistagem; e a terciária, que visa limitar a prevalência de incapacidades crônicas ou de recidivas (Leavell e Clark, 1976). O Estado do bem-estar social da segunda metade do século XX reforça a lógica econômica, especialmente em decorrência da evidente interdependência entre as condições de saúde e de trabalho, responsabilizando-se pela implementação da prevenção sanitária.

Instituem-se, então, os sistemas de previdência social, que não se limitam a cuidar dos doentes, mas organizam a prevenção sanitária. A princípio, pressupunham uma diferenciação entre assistência social, destinada às classes mais desfavorecidas e baseada no princípio de solidariedade e, portanto, financiada por fundos públicos estatais, e previdência social, mecanismo assecuratório restrito aos trabalhadores. Entretanto, exatamente porque a prevenção sanitária era um dos objetivos do desenvolvimento do Estado, logo se esclarece o conceito de seguridade social, que engloba os subsistemas de assistência, previdência e saúde públicas. Trata-se, portanto, de identificar a responsabilidade a priori do Estado. Assim, quanto aos estilos de vida, verifica-se um grande investimento estatal."

Especificamente sobre saúde no Brasil, a Constituição Federal de 1988, em seu art. 196, estabelece que a saúde é direito de todos e dever do Estado, garantido mediante políticas sociais e econômicas que visam à redução do risco de doença e de outros agravos e ao acesso universal e igualitário às ações e serviços para sua promoção, proteção e recuperação. Vê-se in claris o princípio da universalidade e da isonomia.

O art. 198 da Constituição Federal de 1988 traz ainda a previsão de integração das ações e serviços públicos de saúde numa rede regionalizada e hierarquizada e constituindo um SISTEMA ÚNICO, organizado de acordo com as seguintes diretrizes:

I - descentralização, com direção única em cada esfera de governo;

II - atendimento integral, com prioridade para as atividades preventivas, sem prejuízo dos serviços assistenciais;

III - participação da comunidade.

Os entes federativos possuem competência concorrente em matéria sanitária (art. 24, XII da Constituição Federal de 1988). No âmbito da legislação concorrente, a competência da União está limitada ao estabelecimento de normas gerais. A competência da Uniāo para legislar sobre normas gerais não exclui a competência suplementar dos Estados e, inexistindo lei 
federal sobre normas gerais, os Estados exercerão a competência legislativa plena (dentro do plano regional).

A superveniência de lei federal sobre normas gerais suspende a eficácia da lei estadual, no que lhe for contrária. Tudo isto demonstra que há uma descentralização, que inclusive foi seguida pela legislação infraconstitucional. A Lei n. 8.080/90, v. g., que regula o SUS (Sistema Único de Saúde) segue um modelo descentralizado, incutindo grande relevância na participação dos Municípios neste cenário. Logo, a União trata do caráter mais abrangente da saúde (nacional), Estados e Distrito Federal, de questões regionais e Municípios, dos aspectos locais. Sem hierarquia. Num sentido único e cooperativo.

O atendimento integral é fruto da universalidade objetiva, sendo que a prioridade para as atividades preventivas, sem prejuízo dos serviços assistenciais, é oriunda da razoabilidade. Como diria São Jerônimo, sancta simplicitas: é melhor prevenir que remediar. E remediar faz mais sentido quando se trata de saúde. Previnam-se as doenças, mantendo-se o atendimento para os já enfermos. Tal prevenção envolve um conceito amplo de saúde, associado com o equilíbrio físico, o psicológico e o social.

$E$, quanto à participação da comunidade, esta tem ocorrido por meio de conselhos participativos, principalmente na seara dos Municípios. Ouvem-se os munícipes, quanto aos anseios locais da população.

Finalmente, o art. 200 da Constituição Federal giza as atribuições do sistema único de saúde (não taxativamente):

1 - controlar e fiscalizar procedimentos, produtos e substâncias de interesse para a saúde e participar da produção de medicamentos, equipamentos, imunobiológicos, hemoderivados e outros insumos;

II - executar as ações de vigilância sanitária e epidemiológica, bem como as de saúde do trabalhador;

III - ordenar a formação de recursos humanos na área de saúde;

IV - participar da formulação da política e da execução das ações de saneamento básico;

$\mathrm{V}$ - incrementar em sua área de atuação o desenvolvimento científico e tecnológico;

VI - fiscalizar e inspecionar alimentos, compreendido o controle de seu teor nutricional, bem como bebidas e águas para consumo humano;

VII - participar do controle e fiscalização da produção, transporte, guarda e utilização de substâncias e produtos psicoativos, tóxicos e radioativos;

VIII - colaborar na proteção do meio ambiente, nele compreendido o do trabalho.

Estas diretrizes confirmam o alcance de um conceito amplo de saúde, associado com o equilíbrio biológico, físico, psicológico e social. O sentido 
estatal protetivo do homem enquanto ser que vive em coletividade, visando dar guarida aos chamados direitos humanos sociais, se manifesta com plenitude dentro dos limites da Seguridade Social constitucional. Os fatores sociais são interdependentes.

\section{CONCLUSÃO}

O âmbito constitucional ligado à saúde deve sempre ser analisado (direta ou indiretamente) sob o prisma da Seguridade Social. Há uma vinculação com os princípios elencados supra, no art. 194 da Constituição Federal de 1988. Não obstante a sistemática constitucional e os princípios correlatos, a doutrina e a jurisprudência são também específicas quando se trata do assunto Seguridade Social e seus três elementos.

Portanto, o caráter coletivo fundamenta o presente estudo, segundo 0 qual analisar o Direito Sanitário ou o direito à saúde de forma independente da Seguridade Social é efetuar um trabalho cientificamente incompleto.

\section{REFERENCIAS}

BALERA, Wagner. Sistema de seguridade social. 2. ed. São Paulo: LTr, 2002. (Coord.). Curso de direito previdenciário. 4. ed. São Paulo: LTr, 1998.

BOBBIO. Norberto. A era dos direitos. 8. ed. Rio de Janeiro: Campus, 1992. et al. Dicionário de política. 5. ed., Brasília: Ed. da UnB, 1993.

BUDIB, Alexandre Carlos. Benefícios de assistência social. Dissertação (Mestrado) - Pontifícia Universidade Católica. São Paulo, 2004.

DALLARI, Sueli Gandolfi. O princípio da precaução dever do estado ou protecionismo disfarçado? Disponível em: <http://www.scielo.br/scielo.php?script=sci_ arttext\&pid=S0102-88392002000200007>. Acesso em: 22.dez.2005.

DURAND, Paul. La política contemporánea de seguridad social. Madrid: Ministerio de Trabajo y Seguridad Social, 1991.

MARTINS, Sérgio Pinto. Direito da seguridade social. 17. ed. São Paulo: Atlas, 2002.

SARLET, Ingo Wolfgang. A eficácia dos direitos fundamentais. Porto Alegre: Livraria do Advogado, 2001. 